\title{
Dietary supplement of Yunkang 10 green tea and treadmill exercise ameliorate high fat diet induced metabolic syndrome of C57BL/6 J mice
}

Yanzhong Zhang ${ }^{1,2 \dagger}$, Mingxing $\mathrm{Gu}^{2 \dagger}$, Ruru Wang ${ }^{2 \dagger}$, Menwan $\mathrm{Li}^{2}$, Daxiang $\mathrm{Li}^{2}$ and Zhongwen $\mathrm{Xie}^{2^{*}}$ (D)

\begin{abstract}
Background: Diet and exercise play important roles in ameliorating metabolic syndrome. Yunkang 10 (Camellia sinensis var. assamica) is a most cultivated tea variety for making tea in the Southwestern China. Currently, there is no report of healthy effects of Yunkang 10 green tea (YKGT) and treadmill exercise (Ex) on high fat diet induced metabolic syndrome (MetS). We aimed to investigate the beneficial effects and molecular mechanism of YKGT and Ex using high fat diet induced MetS of C57BL/6 mice.
\end{abstract}

Methods: Catechins and caffeine in water extract of YKGT were measured via high performance liquid chromatography (HPLC). 10-week old mice were fed with high fat diet (HFD) for 10 weeks to induce obese mice. Then the obese mice were fed with continuous high fat diet (HFD), HFD with YKGT, HFD with Ex, and HFD with both YKGT and Ex for 8 weeks, respectively. The another group of 10-week old mice fed with low fat diet (LFD) were used as control.

Results: HPLC data revealed that YKGT has abundantly high concentration of epigallocatechin gallate (EGCG) and caffeine compared to Longjing 43 (Camellia sinensis var. sinensis) green tea. YKGT and Ex significantly decreased the level of blood glucose, serum total cholesterol (TC), triglyceride (TG), insulin, and alanine aminotransferase activity (ALT) when compared to HFD group. The fatty liver and hepatic pro-inflammatory gene expression in the YKGT, Ex and YKGT+Ex groups was mitigated significantly compared with HFD group, respectively. The phosphorylation of inhibitor of nuclear factor kappa-B kinase $\alpha / \beta$ (IKKa/ $\beta$ ) and inhibitor of nuclear factor kappa-B a (IkBa) protein in the nuclear factor kappa-light-chain-enhancer of activated B cells (NF-kB) signaling pathway was also decreased in YKGT or YKGT+Ex groups. The combination of YKGT and Ex prevented gene expression for lipid synthesis in the liver tissue, and significantly upregulated mRNA level of glucose transport genes in the skeletal muscles, when compared to the HFD group.

Conclusions: This study demonstrated that YKGT supplement or exercise appeared to reverse preexisting metabolic syndrome, and effectively relieved the fatty liver and hepatic inflammatory response induced by high fat diet. YKGT supplement and treadmill exercise together had better beneficial effects than only one intervention.

Keywords: Yunkang 10 green tea, Exercise, Metabolic syndrome, Skeletal muscle, inflammation, RNAseq

\footnotetext{
* Correspondence: zhongwenxie@ahau.edu.cn

†Yanzhong Zhang, Mingxing Gu and Ruru Wang contributed equally to this work.

${ }^{2}$ State Key Laboratory of Tea Plant Biology and Utilization, School of Tea and Food Sciences and Technology, Anhui Agricultural University, 130 West Changjiang Road, Hefei, Anhui Province 230036, People's Republic of China Full list of author information is available at the end of the article
}

(c) The Author(s). 2020 Open Access This article is distributed under the terms of the Creative Commons Attribution 4.0 International License (http://creativecommons.org/licenses/by/4.0/), which permits unrestricted use, distribution, and reproduction in any medium, provided you give appropriate credit to the original author(s) and the source, provide a link to the Creative Commons license, and indicate if changes were made. The Creative Commons Public Domain Dedication waiver (http://creativecommons.org/publicdomain/zero/1.0/) applies to the data made available in this article, unless otherwise stated. 


\section{Introduction}

Metabolic Syndrome (MetS) is a group of chronic metabolic disorders including obesity, hyperglycemia, dyslipidemia and hypertension. The risk for developing MetS is closely related to dietary and lifestyle, such as consumption of a high-fat diet, less exercise. MetS has been a strong risk factor for cardiovascular disease, diabetes and cancer [1]. Over the past decades, rapid development of economy and technology has resulted in increasing food supply and declining physical activity $[2,3]$. Sedentary lifestyle and over eating habits are considered to be primarily responsible for the growing rate of obesity, diabetes and other MetS associated diseases across the world [4, 5]. The data from International Diabetes Federation (IDF) showed that the global diabetes population reaches 425 million, and undiagnosed diabetes has 212 million in 2017. According to the World Health Organization (WHO) in 2016, nearly 2 billion adults worldwide were overweight and, of these, more than half a billion were obese. Although the great progress has been made in the treatment of MetS by surgery and pharmacology, some potential side effects are inevitable all the time $[6,7]$. At present, lifestyle improvement, diet intervention and exercise therapy are the basic strategies for prevention of MetS. Recent findings indicated that extended sedentary time in individuals with type 2 diabetes is associated with glucose intolerance and higher risk for development of cardiovascular diseases (CVD) [8, 9]. Aerobic exercise reduces blood pressure in both hypertensive and normotensive persons, increase insulin sensitivity and enhance immune function [10, 11]. Regular exercise training increases oxidative capacity, lipid metabolism, reduces serum triglycerides, blood pressure, insulin resistance $[12,13]$.

Tea has been very popular in the world. And its consumption is only second to water [14]. It has been widely recognized that tea has healthy effects on lipid lowing and anti-obesity $[15,16]$. In the processing of green tea, polyphenol oxidase is inactivated by either steaming or pan-frying fresh tea leaves to save the polyphenols. Green tea contains high amount of a monomeric polyphenolic compound known as catechin and (-)-epigallocatechin gallate (EGCG), which is a major component of catechins and was the most studied in recent years. Many reports have previously demonstrated that catechins, especially EGCG, improve insulin resistance [17, 18], promote fat oxidation, lower blood total cholesterol and triglycerides, and reduce body weight [14, 19, 20]. Yunkang 10 (Camellia sinesis var. assamica cv. Yun Kang 10), is a widely cultivated tea cultivar in Southwestern China. It bears the advantages of wide range of adaptability, low-cost cultivation, and quick growth rate over other's cultivars. The genome, chemical profiling, volatile components, entophytic bacteria of Yunkang 10 have been reported [21-24]. Until now, there is no report to evaluate its healthy values against MetS. Because teas are consumed by drinking water infusion or grinding powders of whole-leaf teas, it is very curious to know the beneficial effects and underlying mechanism by dietary supplement of whole tea powder using HFD induced obese mice.

Previous studies reported that a combination of green tea and exercise facilitates sports performance and endurance capacity, and effectively prevents obesity [25-27]. However, there is limited information on therapeutic effect of green tea supplement combined with aerobic exercise for ameliorating excisting MetS. The goal of this study is to investigate if the combination of Yunkang 10 green tea supplement and physical exercise has synergistically therapeutic effects on MetS induced by HFD in C57BL/6 J mice, and if so, what are underlying mechanisms?

\section{Materials and methods \\ Samples preparation and analysis of catechins and caffeine}

Tea cultivar Yunkang 10 (Camellia sinensis var. assamica) was cultivated in Menghai County, Yunnan Province, China. Yunkang green tea (YKGT) was provided by Tea Research Institute of the Yunnan Province. Tea cultivar Longjing 43 (Camellia sinensis var. sinensis) was from tea garden of Anhui Agricultural University, Anhui Province, China. Longjing green tea (LJGT) was prepared by a professional tea producer following a standard protocol. The main catechins and caffeine were analyzed following our previous protocol [14] on a Waters High Performance Liquid Chromatography (HPLC) system supported with a Waters 600 controller and Waters 2489 UV/Visible Detector $(280 \mathrm{~nm})$.

\section{Animal experiments design and treatment}

Male C57BL/6 J mice (age of 9 weeks, weight $26.1 \pm$ $0.26 \mathrm{~g}$ ) were purchased from the National Resource Centre of Model Mice (Nanjing, China) and allowed to acclimate to the environment for 1 week on a specific pathogen free (SPF) laboratory animal facility center at Anhui Agricultural University. The animal facility was controlled with a constant temperature $\left(22 \pm 1{ }^{\circ} \mathrm{C}\right)$ and humidity $(50 \pm 5 \%)$ under a $12: 12 \mathrm{~h}$ light-dark cycle falls on 8:00 a.m. to 8:00 p.m. All animals were housed in cages and provided with food and water ad libitum.

At 10 weeks of age, the mice were divided into lowfat-diet group (LFD, $n=10$ ), and high-fat-diet group (HFD, $n=40$ ). The LFD has $11 \%$ of energy derived from fat, $3.6 \mathrm{kcal} / \mathrm{g}$ (AIN93) and HFD is 60\% of energy derived from fat, $5.2 \mathrm{kcal} / \mathrm{g}$. YKGT was crushed into 
powder by BLENDER $800 \mathrm{~S}$ (Warning, Corp., Torrington, CT, USA), and was added into HFD at the concentration of $5 \%(\mathrm{w} / \mathrm{w})$. All diets were obtained from Trophic Animal Feed High-Tech Co., Ltd. (Nantong, China). Metabolic syndrome was induced by feeding the animals with a high fat diet for 10 weeks ad libitum. The model is consistent with previously published $[28,29]$.

At 20 weeks of age, 10-week HFD induced obese mice were randomly divided into four groups: HFD group (HFD, $n=10)$, HFD + YKGT group (GT, $n=10)$, HFD + Ex group $(\mathrm{Ex}, n=10)$, and HFD + YKGT+Ex group $(\mathrm{GT}+\mathrm{Ex}, n=10)$. The exercise mice received a forced treadmill (Zhenghua Bio-Equipment Co, Anhui, China) running for 8 weeks ( 6 days per week) during the experimental period. Mice were placed on the treadmill in their respective lanes undisturbed for $15 \mathrm{~min}$ for their acclimated to the treadmill prior to exercise. In order to avoid injury, the mice were warmed up at slow initial speeds at $6 \mathrm{~m}$ per min before running at higher speed at $8 \mathrm{~m}$ per min. Additional file 1: Table S1 shows the detailed treadmill running schedule.

Food intake and water consumption were monitored every day. Body weight was obtained with a weight scale weekly. Fasting blood glucose was recorded using Nova StatStrip XpresstM Glucose CR Meter (Nova Biomedical, Waltham, UK) with Nova StatStrip XpresstM Glu-test Strips (Nova Biomedical, Waltham, UK) every week. All the animal experimental procedures imposed in this study were in accordance with guidelines of institutional animal care and use committee (IACUC) of Anhui Agricultural University.

\section{Serum and tissue samples collection}

At 28 weeks of age, after 8 weeks therapeutic treatment, upon overnight fasting, animals were anesthetized by intraperitoneal injection of pentobarbital sodium $(50 \mathrm{mg} /$ $\mathrm{kg}$ ), and were sacrificed after peripheral blood collection from the ophthalmic vein. Serum was obtained by centrifugation at $3000 \mathrm{rpm} / \mathrm{min}$ for $5 \mathrm{~min}$ at $4{ }^{\circ} \mathrm{C}$, then stored at $-80^{\circ} \mathrm{C}$. Liver weight was measured on a scale. All other tissue samples were harvested for further biochemical, molecular and immunostaining analyses. A small piece of liver tissues and a piece of soleus muscle tissues were preserved in RNA stabilization solution (Thermo Fisher Scientific, Baltics, USA) for gene expression analysis and RNAseq, respectively. And small pieces of liver tissues were fixed in formaldehyde solution (ZHANYUN, Wuxi, China) for histological experiment, and the rest of liver tissues were immediately liquid nitrogen frozen before stored at $-80^{\circ} \mathrm{C}$ for protein expression studies.

\section{Serum biochemical analysis}

The levels of triglyceride (TG), low-density lipoprotein cholesterol (LDL), high-density lipoprotein cholesterol (HDL), and total cholesterol (TC) in the serum were measured using micro test kits (Johnson Medical Equipment Co., Ltd., Shanghai, China). Serum insulin level was measured using the protocol of Rat/Mouse Insulin ELISA Kit (EMD Millipore Corporation, Billerica, MA, USA). The enzymatic activity of alanine transaminase (ALT) was analyzed with enzyme kits in accordance with the manufacturer's instruction (Nanjing, Jiancheng Biotechnology Co., Ltd., Nanjing, China). OD values were determined by enzyme micro-plate reader (SpectraMaxR i3X Molecular Devices, LLC. California, USA).

\section{Quantitative real-time PCR}

Total RNA was extracted from liver tissue fixed in RNA stabilization solution using Trizol reagent (Vazyme Biotech Co., Ltd., Nanjing, China) following the manufacturer's instruction. The $2 \mu \mathrm{g}$ of total RNA was reverse transcribed to cDNA using Hiscript II 1st strand cDNA Synthesis Kit (Vazyme Biotech Co., Ltd., Nanjing, China). Real-Time PCR was performed with SYBR Green Master Mix using Real-Time PCR Detection System (CFX96 Touch, Bio-Rad, USA) following the previous protocol [30], the expression of 36B4 was used as housekeeping gene to normalize target gene [31]. Primer sequences are designed for mice and listed in Additional file 2: Table S2.

\section{Western blot analysis}

Western blot was performed following the method described previously [32]. In brief, a small piece of liver tissue was immersed in $10 \%$ trichloroacetic acid solution and frozen at $-80^{\circ} \mathrm{C}$ for $24 \mathrm{~h}$. The $100 \%$ acetone was used to wash the liver sample to remove trichloroacetic acid. Then the liver tissue was homogenized in 2XSDS buffer. The protein concentration was determined by BCA Assay kit (Vazyme Biotech Co., Ltd., Nanjing, China). The equal amount of total proteins were separated by SDS polyacrylamide gel electrophoresis and transferred to blotting membranes. The membranes were blocked with defatted-milk buffer, and were further incubated at $4{ }^{\circ} \mathrm{C}$ overnight with primary antibodies including total-IKK $\beta$, phosphorylation-IKK $\alpha / \beta$, total-IkB $\alpha$, phosphorylation-IkB $\alpha$, total and phospho-Akt (Ser473), total and phospho-PI3 Kinase p85 (Tyr458)/p55 (Tyr199), and total and phospho-mTOR (Ser2448) (Cell Signaling Technology, MA, USA), fatty acid synthase (FAS), sterol regulatory element binding protein-1 (SREBP1) and $\beta$-actin (Santa Cruz, CA, USA). The membranes were incubated with appropriate HRP conjugated secondary antibody (Santa Cruz, CA, USA). Protein bands were visualized using ECL developing solution (Vazyme Biotech Co., Ltd., Nanjing, China). The intensities of protein expression were analyzed using Image J software. $\beta$-actin was used as a internal control.

\section{Hematoxylin-eosin staining}

Briefly, the fixed liver tissues were dehydrated and embedded in paraffin (Paraplast Tissue Embedding Medium, 
LEICA, USA) using modular tissue embedding system (LEICA EG1150 H, USA). The $5 \mu \mathrm{m}$ sections were cut by using fully automated rotary microtome (LEICA RM2255, USA) and mounted in positive charged slides (Adhesion Microscope Slides, CITOGLAS, China). Hematoxylineosin (HE) staining was carried out using HE staining kit (Boster Biological Technology Company, China). All the images were acquired by microscope (LEICA DM500, USA) at 200X. Hepatic adipose infiltration cells were counted manually using Image J software.

\section{RNA sequencing and data analysis}

In each group, three soleus skeletal muscle samples were randomly selected to sequence the transcripts. The TruSeq library was prepared following the method previously described [33]. The fragments per kilobase of transcript per million fragments mapped (FPKM) were calculated by dividing the read count of each transcriptional model with its length and scaling the total per sample to a million, and were used to indicate the expression levels of each sample. A gene expression value in FPKM equal or greater than 1 was considered to be expressed in the sample. The raw sequence data was analyzed following our published method [33]. Briefly, DESeq R package (1.10.1) was applied to analyze differential expression of two groups. The Benjamini and Hochberg approach was used to adjust the resulting $p$ values for controlling the false discovery rate. Genes with a DESeq adjusted $p$ value of $<0.05$ were assigned as differentially expressed.

\section{Statistical analysis}

All results were presented as mean \pm S.E.M. Graph Pad Prism5 software was used for statistical analysis. Multiple groups were compared by one-way or two-way ANOVA with Tukeys test when appropriate. Student's t-test was conducted to determine significantly difference between specific two groups. Differences show statistically significant when $P<0.05$.

\section{Results}

The contents of catechins and caffeine in Yunkang 10 green tea

Green teas are rich in catechins, which were proved to have beneficial effects. Yunkang 10 is a "big leaves" tea plant (Camellia sinesis var. assamica cv. Yunkang 10), and Longjing 43 is a "small leaves" tea plant (Camellia sinesis var. sinensis cv. Longjing 43), which is one of the most cultured tea cultivars in Eastern China. Here, we comparatively measured the contents of catechins and caffeine in Yunkang 10 green tea (YKGT) and Longjing 43 green tea (LJGT). Our data showed that YKGT has obviously higher concentration of total catechins and caffeine compared to LJGT. Among catechins, the amounts of EGCG and epicatechin gallate (ECG) are higher, however epigallocatechin $(\mathrm{EGC}),+$ catechin $(+\mathrm{C})$, gallocatechin gallate (GCG) are lower in YKGT than that of LJGT (Table 1).

\section{YKGT and Ex ameliorated phenotypes of MetS in HFD induced $\mathrm{C} 57 \mathrm{BL} / 6 \mathrm{~J}$ mice}

MetS characterized by obesity, diabetes and dyslipidemia. HFD induced obese mice significantly increased body weight and liver weight (Fig. 1a-b), observed higher concentration of serum glucose, insulin, TC and TG (Fig. 1c-f) compared to LFD mice. The treatment of obese mice with YKGT for 8 weeks significantly decreased the elevated glucose, insulin and TC level in plasma (Fig. 1c, d, f), but did not have obvious effects on reducing body weight, liver weight and plasma TG level

Table 1 Relative concentration of catechin and caffeine in Yunkang 10 and Longjing 43 green tea (Dry weight \%)

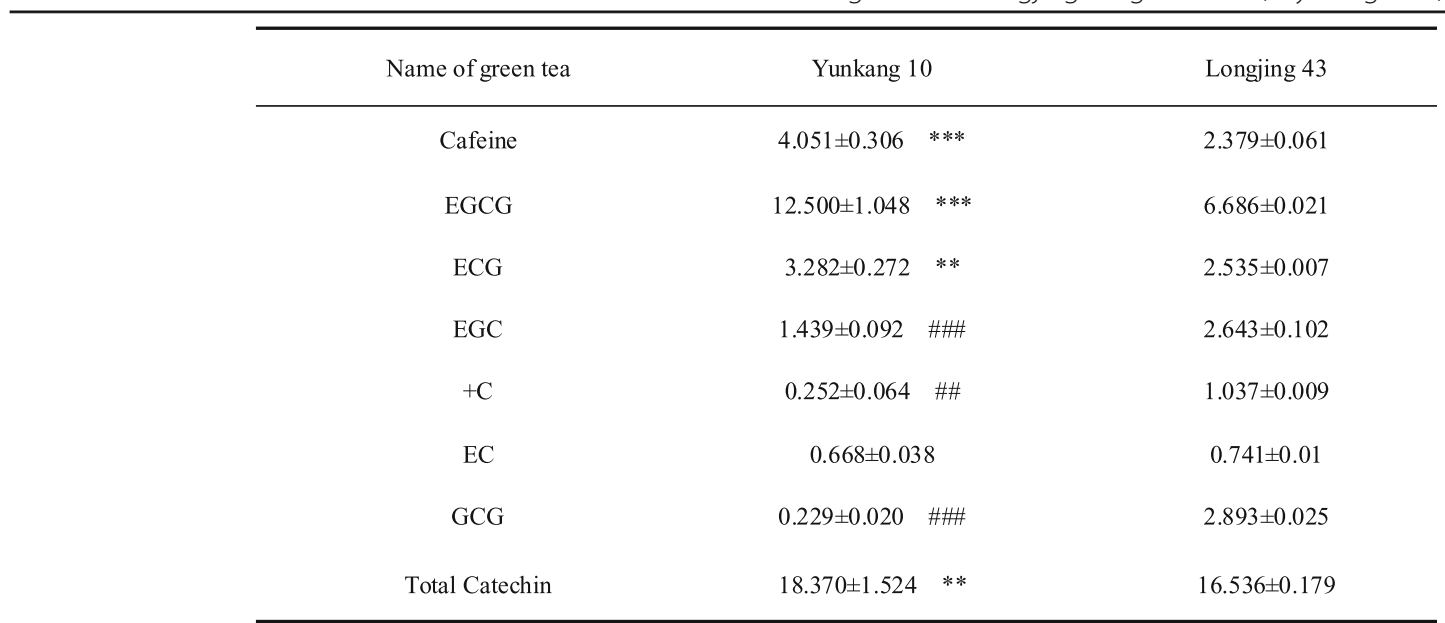

Data were expressed as mean $\pm \operatorname{SEM}(n=3) .{ }^{* *} p<0.01,{ }^{* * *} p<0.001$ when compared with Longjing 43 up-regulation

\#\# $p<0.01,{ }^{\# \# \#} p<0.001$ when compared with Longjing 43 down-regulation 

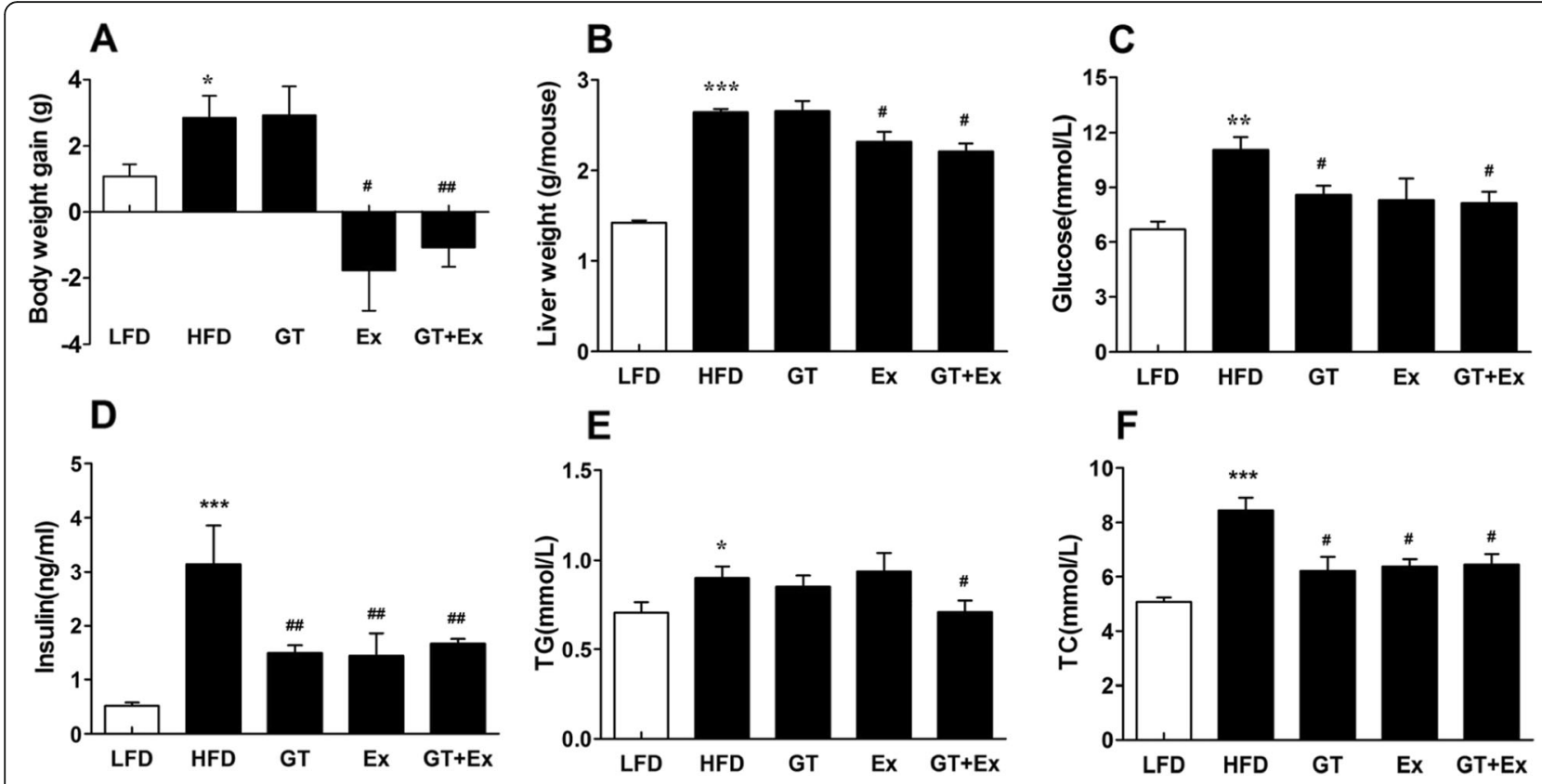

Fig. 1 Improvement of phenotypes of MetS of HFD mice treated with GT, Ex or GT + Ex for 8 weeks. Notes: Body weight gain (a); liver weight (b); serum glucose $(\mathbf{c})$; insulin $(\mathbf{d})$, total cholesterol, TC (e), triglyceride, TG (f). Values given are mean \pm SEM, $n=5 \sim 7 . ;{ }^{*} P<0.05$, ** $P<0.01$, ${ }^{* * *} P<0.001$ when compared with LFD; ${ }^{\#} P<0.05,{ }^{\# \#} P<0.01$ when compared with HFD

(Fig. 1a, b, e). Ex for 8 weeks reduced body weight, liver weight, as well as decreased plasma insulin and TG level of obese mice. However, treatment of obese mice with combination of YKGT and Ex significantly deceased body weight, liver weight, and attenuated the elevation of all observed plasma parameters, glucose (by 26.3\%), insulin (by $46.8 \%$ ), TG (by 21.3\%) and TC (by 23.7\%) compared to continuous HFD feeding obese mice, respectively (Fig. 1c-e).

Histopathological sections of liver tissue illustrated that the HFD mice displayed aberrantly fatty hepatocytes. In contrast, clear hepatic lobule without any lipid droplets of normal hepatic architecture was observed in LFD mice. However, treatment with YKGT, Ex or both YKGT and Ex restored the normal liver architecture with minimal deposition of fat droplets in hepatocytes (Fig. 2a-f). In addition, treatment of obese mice with Ex or YKGT plus Ex significantly decreased the activity of alanine aminotransferase (ALT) in liver of obese C57BL/ 6 mice (Fig. 2g).

YKGT and Ex improved liver lipid and glucose metabolism in HFD induced $\mathrm{C} 57 \mathrm{BL} / 6 \mathrm{~J}$ mice

High fat diet significantly up-regulated the expressions of fatty acid synthesis gene Srebf1, Fas, and Acc in the liver of HFD group mice compared to LFD group mice (Fig. 3a-c). Dietary supplement with YKGT alone for 8 weeks did not prevent the overexpression of all these three fatty acid synthesis genes. And Ex alone only showed significant down-regulation $A C C$ gene expression (Fig. 3c). However, the expression level of SREBF1, $F A S$, and $A C C$ all was decreased significantly by combination of YKGT and Ex intervention (Fig. 3a-c). This observation was further demonstrated by the results of western blotting. The hepatic protein expression of both SREBF1 and FAS decreased dramatically in the combined intervention group mice compared to HFD mice (Fig. 4a-d).

Akt (Protein Kinase B)- PI3K (phosphatidylinositol 3kinase) and mTOR (The mammalian target of rapamycin) signaling pathway plays a pivotal role in regulating metabolism of lipid and glucose. Our data showed that phosphorylation of PI3K-Akt-mTOR were all elevated in the liver of HFD group mice. YKGT or Ex intervention decreased the phosphorylation of PI3K and mTOR, respectively. However, YKGT plus Ex attenuated the phosphorylation of all three proteins in the liver of treated group mice (Fig. 4e-j).

\section{YKGT and Ex ameliorated liver inflammation in HFD induced C57BL/6 J mice}

Chronic inflammation is a main pathological cue for MetS. Liver inflammation can cause fatty liver disease. The mRNA expression profile of pro-inflammatory cytokines of $I L-6, I L-1 \beta, M C P-1$ and TNF- $\alpha$ was observed in liver tissue. Our Real Time PCR data showed that expression of all these pro-inflammatory cytokines was significantly up-regulated in the liver of HFD group mice 

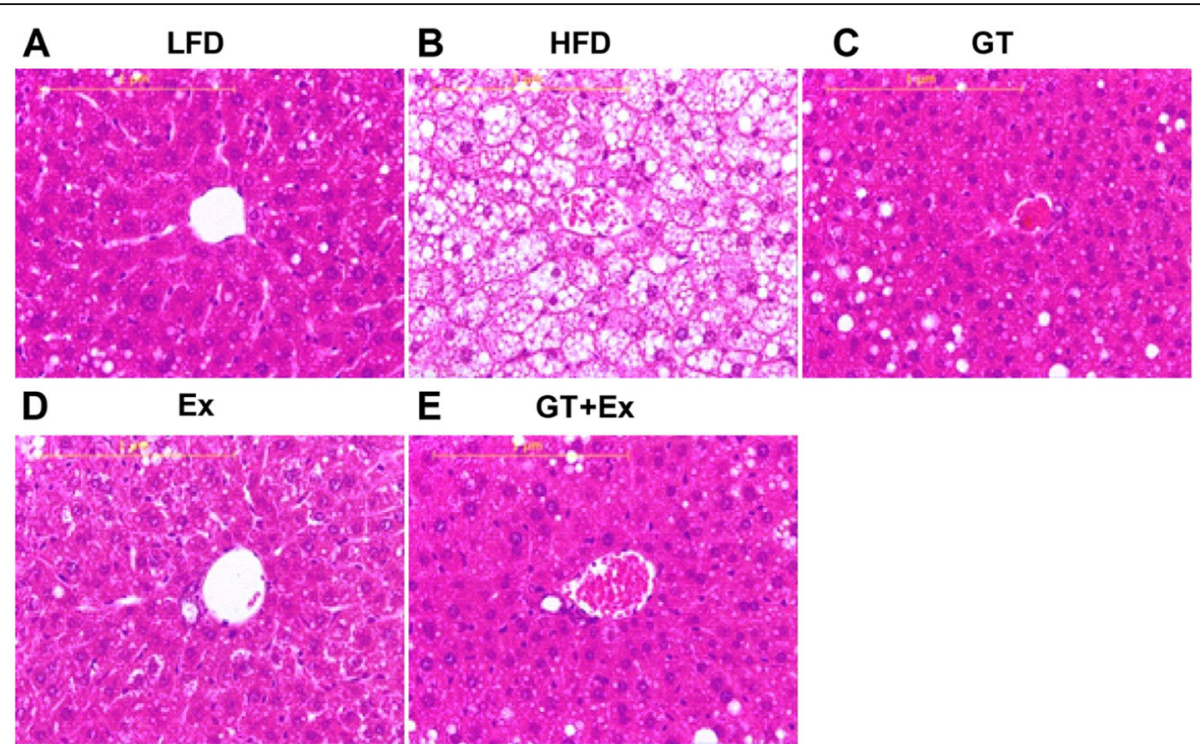

$\mathbf{F}$

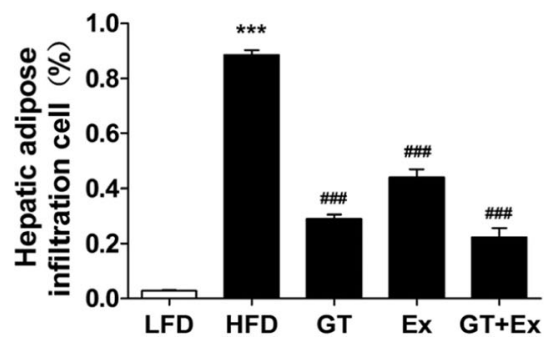

$\mathbf{G}$

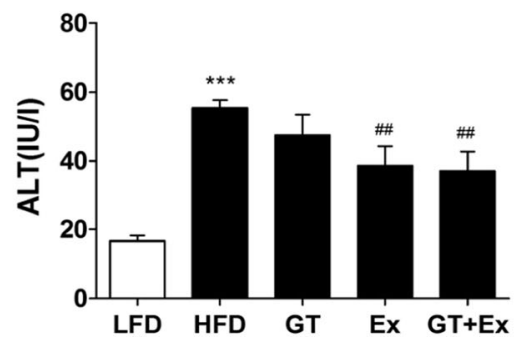

Fig. 2 YKGT, EX and YKGT+EX diets reverse hepatic steatosis and reduce ALT activity. Notes: Hematoxylin-eosin HE staining showing the liver of LFD feeding mice (a); HFD feeding mice (b); HFD with YKGT supplement feeding mice (c); HFD feeding with exercise mice (d); HFD with YKGT supplement feeding and exercise group mice $(\mathbf{e})$; scale bars, $1 \mu \mathrm{m}$. Semi-quantification of hepatocytes with adipose $(\mathbf{f})$; serum $A L T$ activity $(\mathbf{g})$. $N=$ 5 7. ${ }^{* * *} P<0.001$ when compared to LFD; ${ }^{\# \#} P<0.01$, ${ }^{\# \#} P<0.001$ when compared to HFD

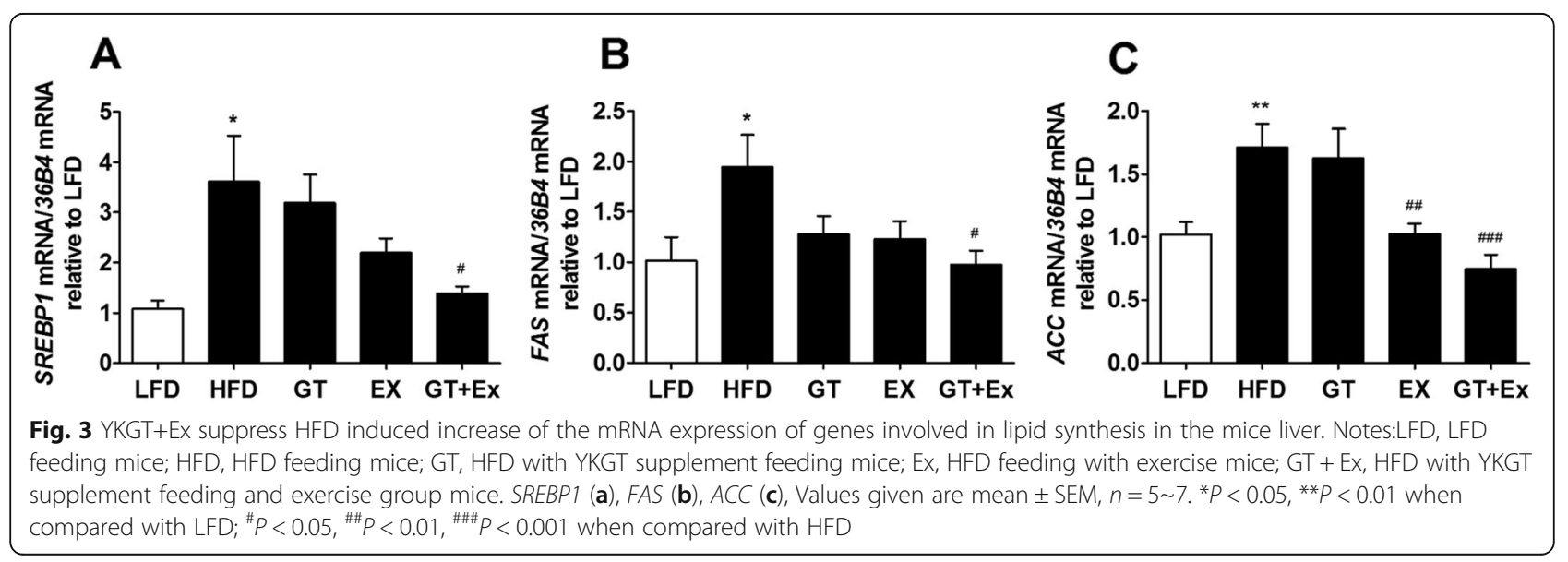




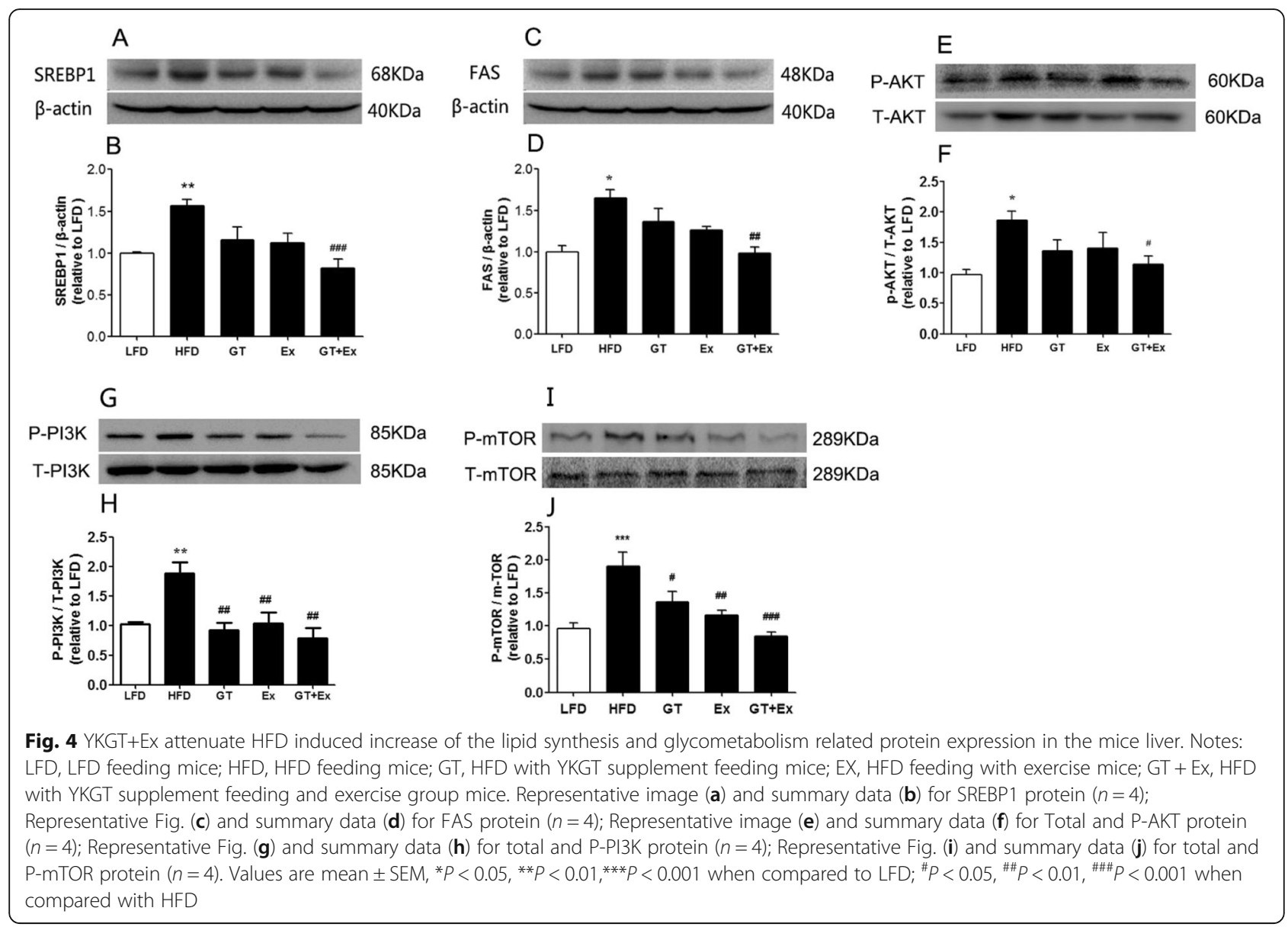

than that of mice fed with LFD. However, treatment of HFD mice with YKGT, Ex or both YKGT and Ex for 8 weeks resulted in profound down-regulation of the cytokines genes expression in mice liver tissue (Fig. 5a-d).

Nuclear factor kappa light chain enhancer of activated $\mathrm{B}$ cells $(\mathrm{NF}-\mathrm{kB})$ is a family of highly conserved transcription factors and a key regulator for cellular inflammatory response. The phosphorylation of inhibitor of $\mathrm{kB}$ kinases (IKK) and inhibitor of $\kappa B \alpha(\mathrm{I} \kappa \mathrm{B} \alpha)$ is a key process for activating inflammatory response of NF- $\kappa B$ pathway. Western blotting data showed that YKGT, Ex or YKG$\mathrm{T}+\mathrm{Ex}$ therapy dramatically prevented the increase of phosphorylated protein expression of IKK $\alpha / \beta$ and IKB $\alpha$ in the liver compared to HFD mice (Fig. $6 \mathrm{a}-\mathrm{d}$ ).

YKGT and Ex altered protein and lipid metabolism and inflammatory pathways in skeletal muscle of HFD induced C57BL/6 J mice revealed by RNAseq data

Liver and muscle are two important tissues for nutrients metabolism. High-throughput sequencing technology was used to analyze RNAseq data from skeletal muscle tissues. Transcriptome sequencing results showed that 1946 genes were up-regulated in the skeletal muscle of HFD group mice compared to that of the LFD group mice. In addition, the numbers of up-regulated genes were significantly reduced after treatment with YKGT, Ex and YKGT plus Ex. (Additional file 3: Figure S1). KEGG pathway analysis of the differentially expressed genes (DEGs) from LF VS HF showed that phagosome and nutrients metabolic pathways (regulation of lipolysis and protein digestion and absorption) are most altered pathways; HF VS Ex DEGs analysis revealed that nutrients metabolic pathways (regulation of lipolysis, PPAR signaling pathway, and protein digestion and absorption) and inflammatory pathway (phagosome, chemokine signaling pathway, NF-kB signaling pathway) are most pathways involved; HF VS YKGT DEGs analysis indicated that inflammatory pathway (chemokine signaling pathway, cytokine-cytokine receptor interaction and phagosome) and nutrients metabolic pathways (protein digestion and absorption, regulation of lipolysis, and PI3K-AKT signaling pathway) are most involved; and HF VS YKGT+Ex DEGs analysis illustrated that ECM receptor interaction, skeletal muscle cell focal adhesion, and nutrients metabolic pathways (protein digestion and absorption, regulation of lipolysis), as well as inflammatory pathway (chemokine signaling pathway, and phagosome) are mostly modulated in skeletal muscle (Fig. 7 a-d). 

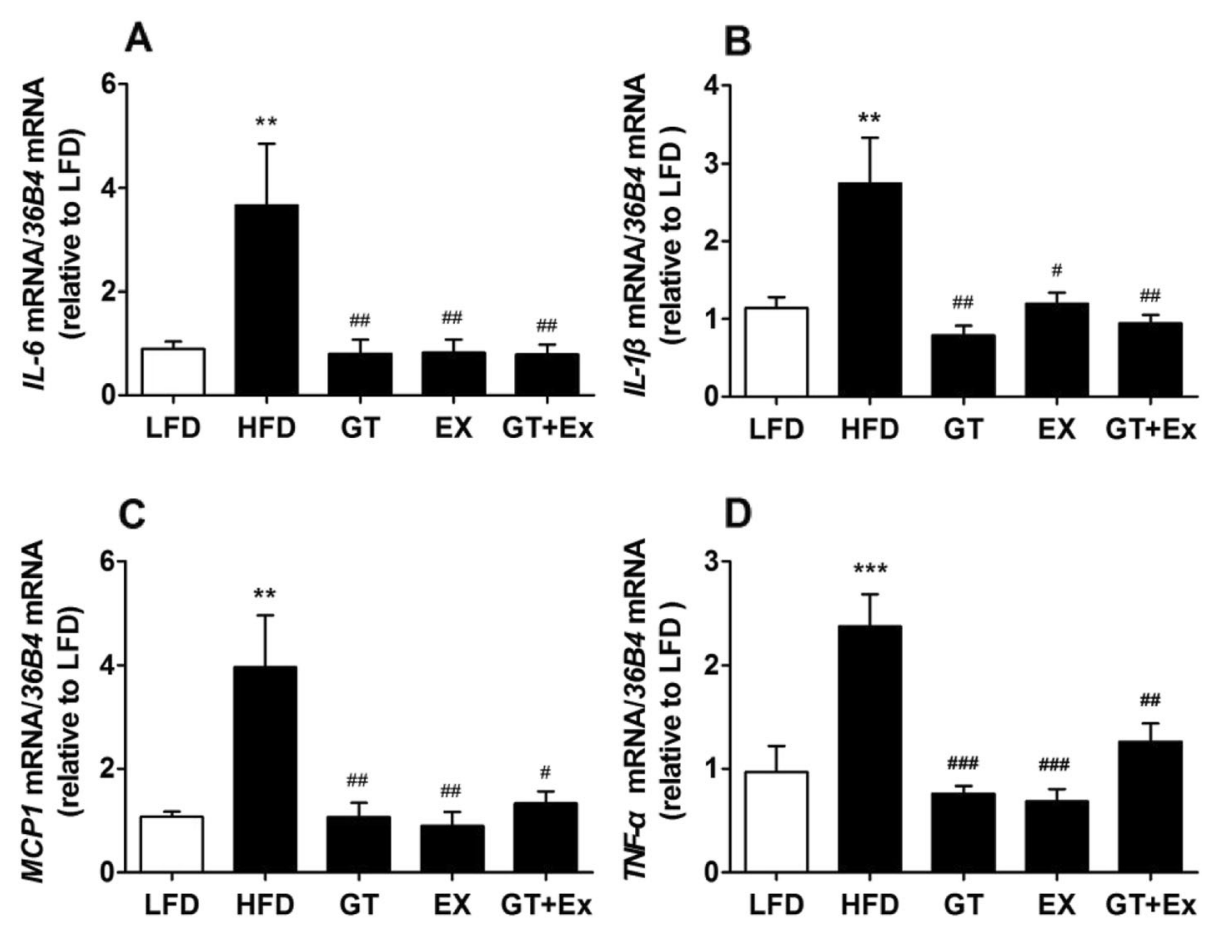

Fig. 5 GT, EX and GT + Ex suppress the HFD induced up-regulation of inflammatory cytokines gene expression level in the liver of various group mice. Notes: LFD, LFD feeding mice; HFD, HFD feeding mice; GT, HFD with YKGT supplement feeding mice; EX, HFD feeding with exercise mice;

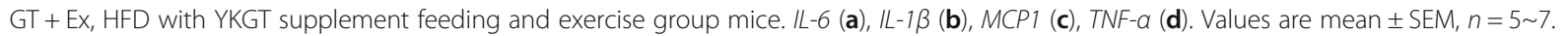

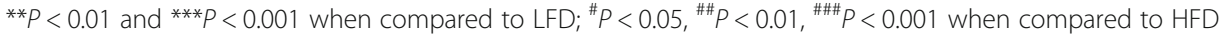

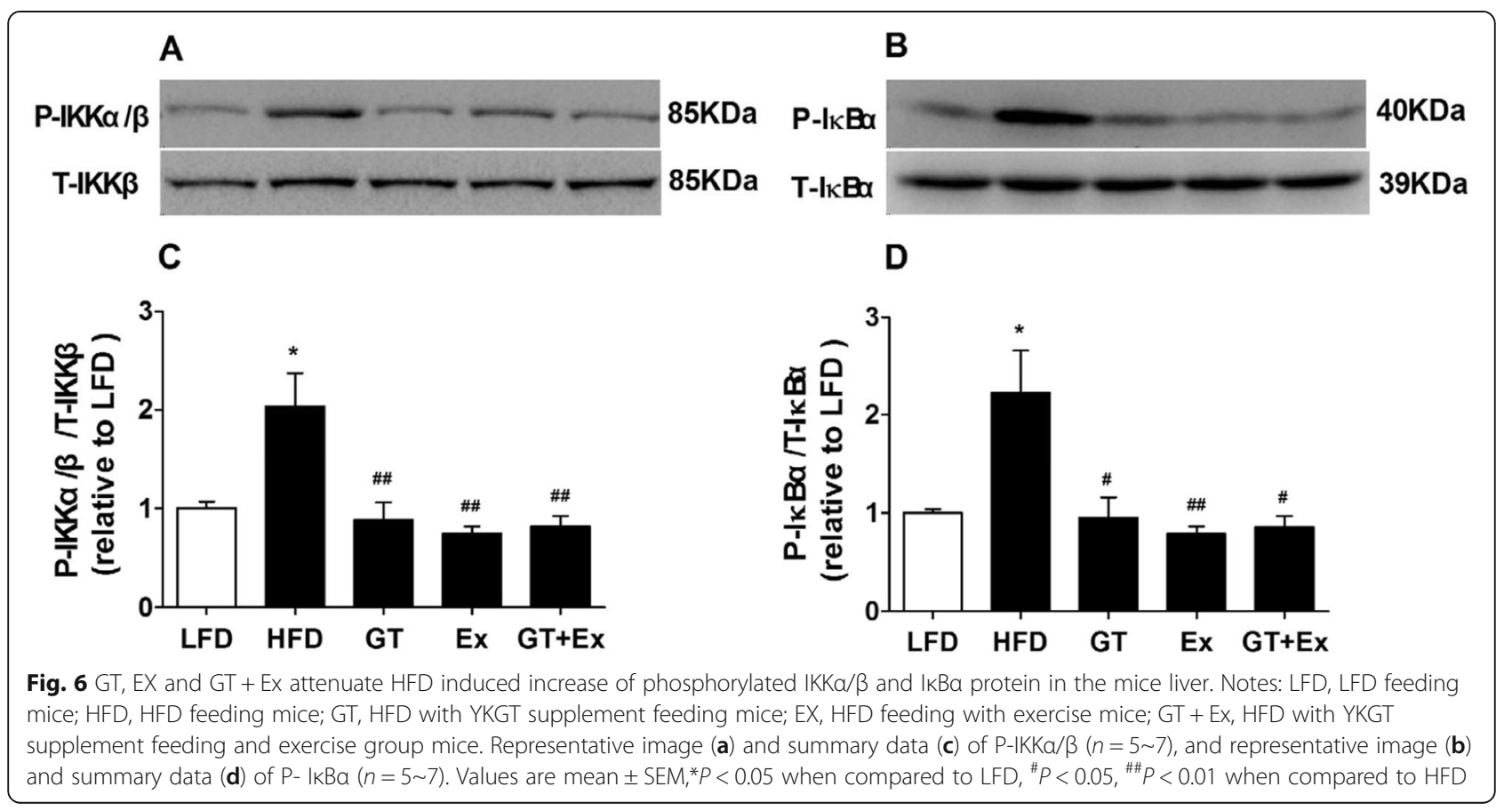




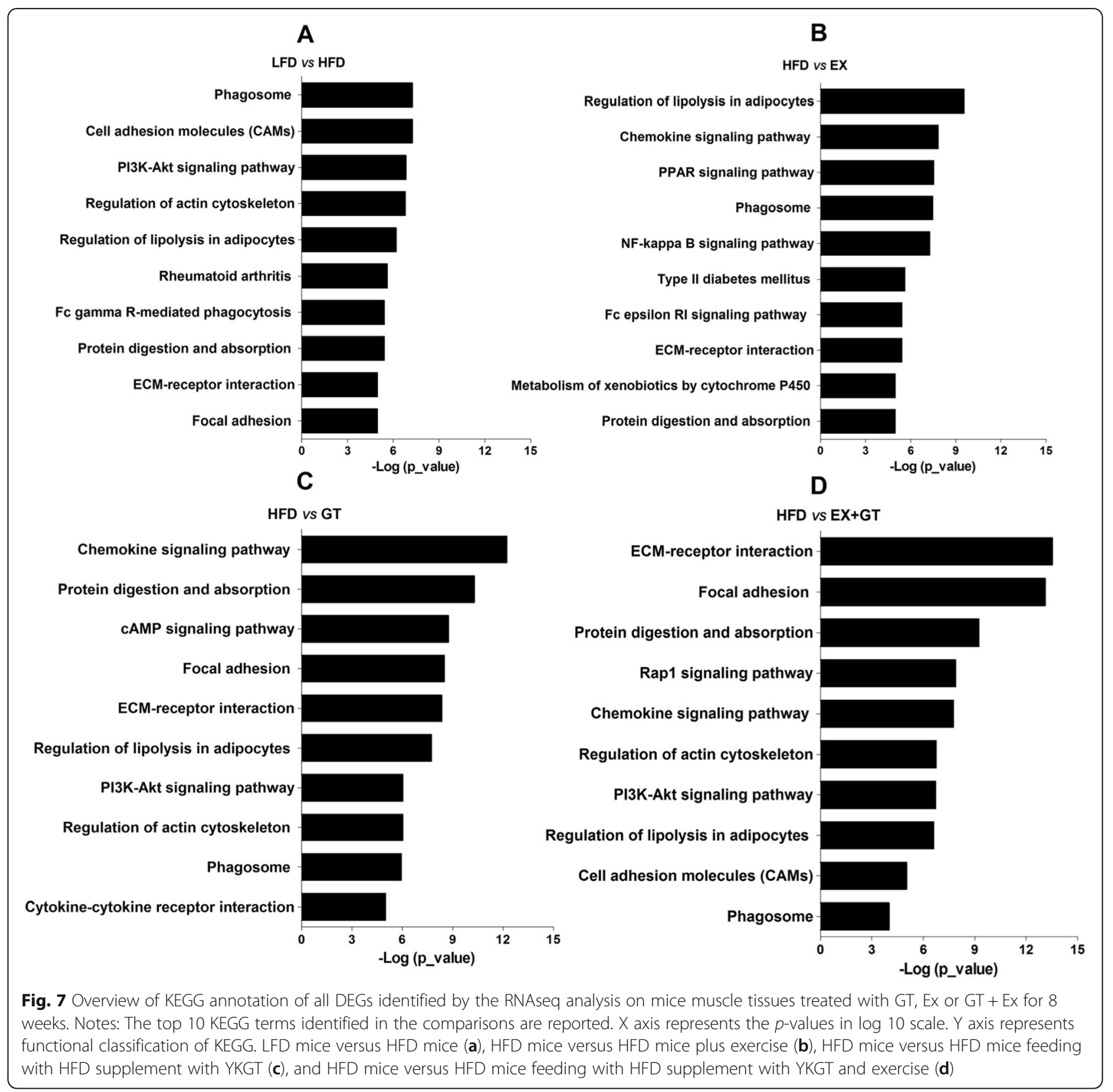

YKGT and Ex ameliorated the expression of genes involved in inflammation and glucose metabolism in skeletal muscle of HFD induced C57BL/6 J mice

Previous analysis of RNAseq data showed that the DEGs were mainly involved in inflammation and nutrients metabolism response to YKGT, Ex or YKGT plus Ex intervention. Based on the gene quantification in Fragments Per Kilobase of transcript per Million mapped reads (FPKM), we found that inflammatory related genes Cd163, Cfh, Il33, C3, Hp, Lbp were down-regulated in the skeletal muscle of YKGT, Ex or YKGT plus Ex group mice compared to HFD induced mice (Fig. 8a-f). And YKGT plus Ex treatment had better effects than that of
YKGT or Ex alone. Glucose transport related genes Prkcd, and Slc2a3 were significantly increased by YKGT, Ex or YKGT plus Ex intervention compared to HFD mice (Fig. 9 b, c), Pea15a, Lep, Irs1 and Irs 2 were obviously decreased in the skeletal muscle by YKGT, Ex or YKGT plus Ex treatment (Fig. 9a, d-f).

\section{Discussion}

Yunkang 10 has been widely cultivated in Southwestern China. However, the potential health effects and relevant molecular mechanisms of YKGT are still unknown. Preventive effects of MetS by green tea and catechins, especially EGCG have been extensively investigated [14-19, 34]. 

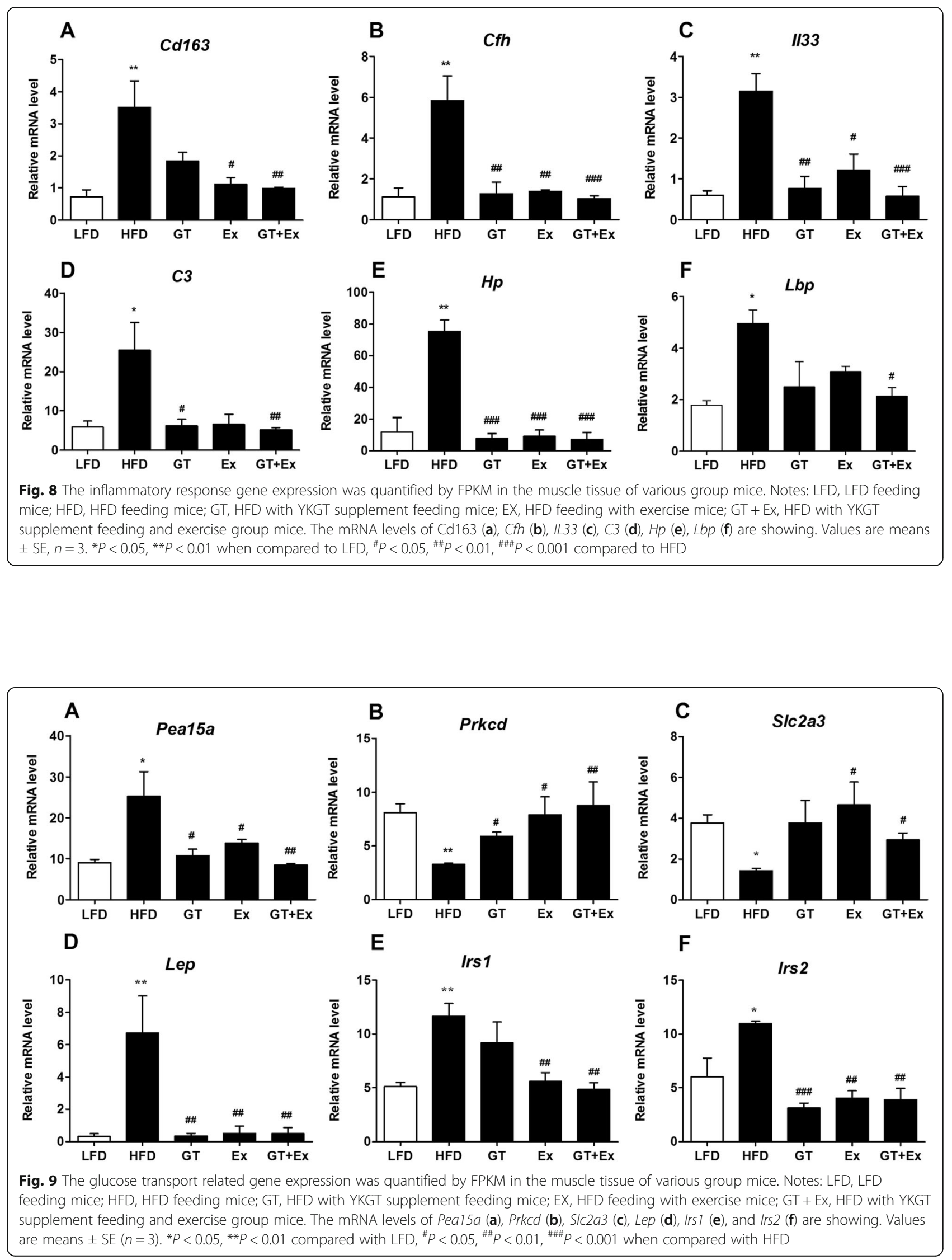
Until today, there is only limited information on therapeutic effects of green tea or EGCG intervention on ameliorating existed MetS [35-37]. During recent years, several studies have reported that a combination of green tea and exercise facilitates sports performance and endurance capacity, and effectively prevents obesity [25-27, 38, 39]. However, the underlying mechanisms are still unclear. The present study investigated therapeutic effects and molecular mechanisms of the combination of YKGT supplement and physical exercise using 10 week HFD induced MetS mice model, which mostly represented MetS of human population.

Obesity, hyperlipidemia and insulin resistance are the major features of the MetS. The mice fed with HFD for10 weeks showed typical MetS phenotype, which include obese, hyperglycemia, hyperlipidemia and hyperinsulinemia, as well as fatty liver. The HFD mice were then treated with YKGT, Ex or YKGT plus Ex for additional 8 weeks. The results showed that treatment with YKGT alone for 8 weeks did not prevent the body weight and liver weight gain, and triglyceride (TG) increase (Fig. 1 a, b, e), but did ameliorate the increase of serum glucose, insulin and total cholesterol level (Fig. 1c, d, f), compared to continuous HFD feeding group mice. Ex alone did restrain the body weight and liver weight gain (Fig. 1a, b), prevented the increase of insulin and total cholesterol level (Fig. 1d, f), and did not inhibit the increase of plasma TG level compared to continuous HFD feeding group mice. However, YKGT plus Ex prevented all these index increases. A randomized trial reported the effect of green tea supplement and interval sprinting exercise (ISE) on the body composition of overweight males, and found that ingestion of green tea by itself did not result in a significant decrease in body or abdominal fat, but increased fat utilization during submaximal exercise. And the combination of 12 weeks of GT ingestion and ISE did not result in greater total and abdominal fat reduction compared to 12 weeks of ISE alone [26]. This result indicated that GT ingestion might not contribute to fat reduction in overweight males. This finding is close correlated to our data that YKGT supplement did not prevent the body weight and liver weight gain, and TG increase. Another randomized control trial suggested that GT catechin consumption enhances exercise-induced deduction in abdominal fat and serum TG [27]. Martin et al. reported that short-term GT supplementation did not affect glucose kinetics following ingestion of an oral glucose load post exercise. However, GT was associated with attenuated insulinemia [40]. Recently, Amozadeh et al. reported a randomized trial for overweight and obese females who participating aerobic training (AT) and green tea supplementation on cardio metabolic risk factors, and found that GT plus AT had better effects on decreasing body weight, body fat percentage, body mass index (BMI), TG, LDL, blood pressure, and heart rate (HR) than that of
GT or AT alone [41]. These results are consistent with our finding.

Next, we investigated the molecular mechanism underlying YKGT and Ex prevented MetS induced by HFD. Sterol regulatory element-binding protein 1 (SREBP1), Fatty acid synthase $(F A S)$ and Acetyl-CoA carboxylase $(A C C)$ are critical enzymes for fatty acid synthesis. Our data showed that the either mRNA expression of SREBP1, $F A S$, or protein expression of SREBP1, FAS were altered by intervention of YKGT or Ex alone in the liver of mice. However, treatment of mice with YKGT plus Ex significantly prevented the increase of gene expression of Srebp1, Fas and ACC (Fig. 3a-c), as well as protein expression of SREBP1 and FAS (Fig. 4a-d). Previous studies reported that GT ameliorated hyperglycemia and improved blood lipid parameters by regulating the expression of FAS, ACC, SREBP-1 genes [42-44]. PI3K-Akt-mTOR signaling pathway was activated in the liver of HFD mice, and YKGT and Ex intervention block this activation by phosphorylation (Fig. 4e-j). PI3K-Akt signaling pathway modulated lipid synthesis genes by regulating transcriptional factor 1 SREBP-1 [45]. In addition, PI3K-AktmTOR1 participated lipid and glucose metabolism by regulating the secretion of very-low-density lipoprotein (VLDL) cholesterol, oxidation of fatty acids and hepatic gluconeogenesis [46]. Tea intake prevented lipid accumulation in the liver and adipose tissues [47, 48]. Exercise can effectively increase fat oxidation and energy consumption $[49,50]$. Previous studies reported that GT supplement combined with exercise enhanced fat oxidation in HFD mice and obese adults $[39,51]$. In addition to promote energy expenditure, this study demonstrated that YKGT plus Ex also effectively suppressed fatty acid synthesis in the liver of HFD mice.

Inflammatory response plays a momentous role in the development of MetS $[52,53]$. Numerous inflammatory cytokines are involved in the process of MetS developing into diabetes and cardiovascular disease [54]. Our results showed that YKGT, Ex and YKGT plus Ex significantly prevented the over-expression of pro-inflammatory cytokines $I L-6, T N F-\alpha, I L-1 \beta$ and MCP1 induced by HFD in the mice liver (Fig. 5a-d). And RNAseq data from skeleton muscle tissue also showed that inflammatory related genes, Cd163, Cfh, Il33, C3, Hp, Lbp were all down-regulated by YKGT, Ex or YKGT plus Ex treatment (Fig. 8a-f). Ma S et al. found that Ketogenic Diet and exercise significantly decreased IL-6 concentration in gastrocnemius and plasma [55]. Recently, Cialdella-Kam et al. reported that four-week supplementation of quercetin or green tea extract (GTE) or quercetin plus GTE did not altered inflammatory cytokine level of IL- $1 \beta$, IL- 6 , TNF- $\alpha$ and IFN- $\gamma$ in the plasma of 12-week HFD mice [56]. The difference between our data and this report might due to the different intervention period ( 8 weeks vs. 4 weeks). 
Proinflammatory cytokines are directly regulated by the activation of NFkB. The activation of NF- $\mathrm{kB}$ pathway is a central part of the complex network of inflammatory response. The NF-kB proteins contain multiple subunits, p50 and p65 dimer bounds to IkB $\alpha$ localized in the cytosol under unstimulated condition. The inhibitor of $\mathrm{kB}$ kinase (IKK) complex is phosphorylated once stimulated, and then activated IKK phosphorylated I $\mathrm{I} B \alpha$ proteins, which releases p50 and p65 dimer from complex, p65 transfers to cell nucleus, where binds to specific sites of DNA in promoter region, and induce the synthesis of pro-inflammatory cytokines in the cells [57]. Therefore, the phosphorylation of IKK and IKB $\alpha$ is a key event for NFKB activation. In this study, YKGT, Ex and YKGT plus Ex all blocked the phosphorylation of $I K K \alpha / \beta$ and $I \kappa B \alpha$, and thus inhibited the transcript of pro-inflammatory cytokines. GT polyphenol, major EGCG has found to have an anti-inflammation function. Ueno $\mathrm{T}$ et al. found that EGCG decreased the lipid droplets in hepatic cells and prevented liver injury by the inhibition of NF-kB pathway [42]. In addition, Tipoe et al. illustrated that EGCG decreased the DNA-binding activity of NF-kB and the expression of TNF- $\alpha$, which ameliorated liver inflammation and fibrosis in carbon tetrachloride $\left(\mathrm{CCl}_{4}\right)$-induced liver injury in mice [58].

Besides generating force for movement, skeletal muscle also contributes to health through the use and storage of macronutrients. RNAseq data from soleus muscle tissues showed that treatment with YKGT, Ex and YKGT plus Ex significantly down-regulated most of genes induced by HFD (Additional file 3: Figure S1). KEGG pathway analysis of DEGs revealed that nutrients metabolic pathways (regulation of lipolysis, PPAR signaling pathway, and protein digestion and absorption) and inflammatory pathways (chemokine signaling pathway, NF- $\mathrm{kB}$ signaling pathway and phagosome) are most modulated pathways response to YKGT, Ex or YKGT plus Ex intervention. Hodgson et al. suggested that long term GTE intake accelerates fat metabolism at rest, while facilitates the expression of fat metabolism enzyme genes in the skeletal muscles during exercise, thus decreases adipogenic genes in the liver [19]. Previous studies also demonstrated that a combination of tea catechin intake and frequent exercise prevents obesity efficiently by accelerating fat oxidation in the liver and skeletal muscles and facilitates energy expenditure [27, 59]. Recently, a report found that theabrownin and swinging exercise prevented obesity and insulin resistance by accelerating metabolism of glucose and lipid [60]. Emerging data have revealed that obesity may also negatively alter muscle protein turnover, or the breaking down and rebuilding of functional proteins [61]. Feeding and resistance exercise reduced stimulation of myofibrillar protein synthesis in obese people [62]. One paper reported that GT catechins suppress muscle inflammation and hasten performance recovery after exercise [63].

Type 2 diabetes results from defects in glucose transport in skeletal muscle. And the glucose transport gene 4 (GLU4) is abundant present in the skeleton muscles [64]. Tsai et al. reported that 8-week oral GTE supplementation increased post exercise systemic fat oxidation and exercise-induced muscle GLUT4 protein content [65]. From RNAseq data, we found that glucose metabolic related genes Prkcd and Slc2a3 were promoted by YKGT, Ex or YKGT plus Ex. PRKCD is activated by diacylglycerol (DAG) and involves in glucose metabolic pathway. SLC2A3 is a glucose transmembrane transporter, and facilitates glucose transport in the muscle cell [66]. Obesity decreased sensitivity to leptin, developed leptin resistance [67]. Our RNAseq data showed that YKGT, Ex or YKGT plus Ex significantly decreased leptin gene expression in the skeletal muscle. Murase et al. reported that combination of tea-catechin intake and regular swimming significantly decreased serum leptin level in diet induced obesity C57BL/6 mice [68].

\section{Conclusion}

YKGT is characterized by high concentration of total catechins and caffeine. YKGT supplement only significantly prevented the increase of plasma glucose, insulin and TC level, and Ex alone ameliorated body weight and liver weight increase, and decreased insulin and TC level. However, YKGT plus Ex prevented all these parameters increase, and had better therapeutic effects than that of YKGT or Ex alone for HFD induced MetS mice. HE staining showed that YKGT plus Ex reversed fatty liver, and decreased the serum ALT activity. Mechanistic studies revealed that combination of YKGT and Ex significantly suppressed the key lipid synthesis genes and protein expression in the liver, and significantly upregulated glucose transport genes expression in the skeletal muscles, when compared to the HFD group mice. In addition, the hepatic pro-inflammatory gene expression was mitigated significantly by inhibition of NF-kB activation through decreasing the phosphorylation of $I K K \alpha / \beta$ and $I k B \alpha$ by YKGT, Ex and YKGT plus Ex intervention. RNAseq data from soleus muscle tissues showed that treatment with YKGT, Ex and YKGT plus Ex significantly down-regulated most of genes induced by HFD. KEGG pathway analysis indicated that nutrients metabolic pathways and inflammatory pathways are the most modulated pathways response to YKGT, Ex or YKGT plus Ex intervention compared to HFD mice. The schematic diagram of YKGT plus Ex reversed HFD induced MetS of C57BL/6 J mice is showing in Fig. 10.

This study demonstrated that combination of YKGT supplement and aerobic exercise appeared to reverse preexisting MetS, and effectively relieved the fatty liver 


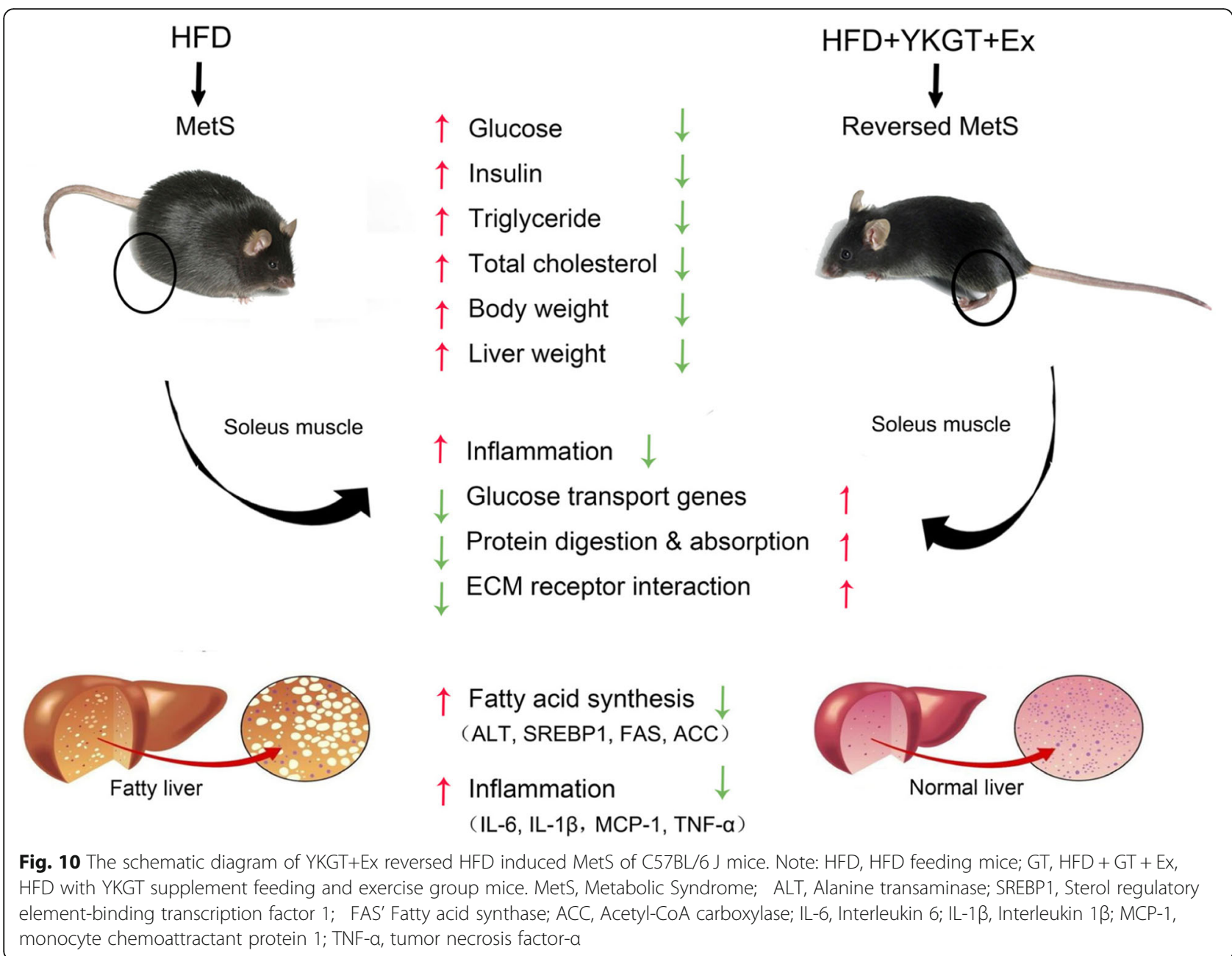

and hepatic inflammatory response induced by HFD. YKGT supplement and aerobic exercise together might be a beneficial strategy for ameliorating MetS of human population. However, adequate intensity and appropriate period of exercise intervention, and YKGT dosage for treatment of MetS require further investigation.

\section{Supplementary information}

Supplementary information accompanies this paper at https://doi.org/10. 1186/s12986-020-0433-9.

Additional file 1: Table S1. The treadmill exercise schedule for HFD mice during the experiment.

Additional file 2: Table S2. Primer sequences used for RT-PCR experiment.

Additional file 3: Figure S1. Diagram representing the percent of genes differentially expressed in each comparison.

\section{Acknowledgements}

We thank Ms. Yun Teng for her excellent technical assistant for animal care.

\section{Authors' contributions}

YZ and MG were responsible for performing the experiments, collecting data, and preparing the manuscript draft; RW and $M L$ were responsible for analyzing the RNAseq data and editing the manuscript; DL conceived the research goals and oversaw the implementation and editing of the. manuscript; ZX was responsible for conceiving the research goals and experimental design, analyzing data, writing, and editing the manuscript. All authors read and approved the final manuscript.

\section{Funding}

This research was funded by a key grant for innovative province from the Department of Sciences and Technology of Anhui Province to Z. X (Grant Number 11080001), the National Sciences Foundation of China to Z.X. (Grant Number 31571207), a grant for Nutrition and Quality \& Safety of Agricultural Products from the Anhui Province Talent Team Program to Z. X, a open grant from State Key Laboratory of Tea Plant Biology and Utilization to Y. Z, and a grant for supporting animal core facility in Anhui Agricultural University from the Department of Sciences and Technology of Anhui Province.

Availability of data and materials The datasets used and/or analysed during the current study are available from the corresponding author on reasonable request.

Ethics approval and consent to participate

All the animal experiments in this study were accordance to ethics guidelines of institutional animal care and use committee (IACUC) and were approved by IACUC of Anhui Agricultural University.

Consent for publication Not applicable. 


\section{Competing interests}

The authors declare no conflict of interest. The founding sponsors had no roles in the design of the study; in the collection, analyses, or interpretation of data; in the writing of the manuscript; or in the decision to publish the results.

\section{Author details}

'Department of Sports Sciences, Anhui Agricultural University, Hefei, Anhui, People's Republic of China. ${ }^{2}$ State Key Laboratory of Tea Plant Biology and Utilization, School of Tea and Food Sciences and Technology, Anhui Agricultural University, 130 West Changjiang Road, Hefei, Anhui Province 230036, People's Republic of China.

\section{Received: 30 September 2019 Accepted: 20 January 2020} Published online: 04 February 2020

\section{References}

1. Wilson PW, D'Agostino RB, Parise H, Sullivan L, Meigs JB. Metabolic syndrome as a precursor of cardiovascular disease and type 2 diabetes mellitus. Circulation. 2005;112:3066-72.

2. Swinburn BA, Sacks G, Hal KD, Mcpherson K, Finegood DT, Moodie ML, Gortmaker SL. The global obesity pandemic: shaped by global drivers and local environments. Lancet. 2011;378:804-14.

3. Moon JY, Wang T, Sofer T, North KE, Isasi CR, Cai J, Gellman MD, Moncrieft AE, Sotres-Alvarez D, Argos M, Kaplan RC, Qi Q. Objectively measured physical activity, sedentary behavior, and genetic predisposition to obesity in U.S. Hispanics/Latinos: Results from the hispanic community health study/study of Latinos (HCHS/SOL). Diabetes. 2017;66:3001-12.

4. Hossain P, Kawar B, Nahas El, M. Obesity and diabetes in the developing world — a growing challenge. New Engl J Med. 2007:356:213-5.

5. Mozaffarian D, Hao T, Rimm EB, Willett WC, Hu FB. Changes in diet and lifestyle and long-term weight gain in women and men. New Engl J Med. 2011;364:2392-404.

6. Inge TH, Courcoulas AP, Jenkins TM, Michalsky MP, Helmrath MA, Brandt ML, Harmon CM, Zeller MH, Chen MK, Xanthakos SA, Horlick M, Buncher CR, Teen-LABS C. Weight loss and health status 3 years after bariatric surgery in adolescents. New Engl J Med. 2016;374:113-23. https://doi.org/10.1056/ NEJMoa1506699.

7. Schiavon CA, Bers-chferreira AC, Santucci EV, Oliveira JD, Torreglosa CR, Bueno PT, Frayha JC, Santos RN, Damiani LP, Noujaim P, Halpern H, Monteiro FLJ, Cohen R, Uchoa CHG, Souza MGD, Amodedo C, Bortolotto $L A$, lkeoka D, Drager LF, Cavalcanti AB, Berwanger O. Effects of bariatric surgery in obese patients with hypertension: The GATEWAY randomized trial (Gastric Bypass to Treat Obese Patients With Steady Hypertension). Circulation. 2017;137:1132-42.

8. Fritschi C, Park H, Richardson A, Park C, Collins EG, Mermelstein RJ, Riesche L, Quinn L. Association between daily time spent in sedentary behavior and duration of hyperglycemia in type 2 diabetes. Biol Res Nurs. 2016;18:160-6

9. Cooper AJ, Brage S, Ekelund U, Wareham NJ, Griffin SJ, Simmons RK. Association between objectively assessed sedentary time and physical activity with metabolic risk factors among people with recently diagnosed type 2 diabetes. Diabetologia. 2014;57:73-82.

10. Whelton SP, Chin A, Xin X, He J. Effect of aerobic exercise on blood pressure: a meta-analysis of randomized, controlled trials. Ann Intern Med. 2002;136:493-503.

11. Colberg SR, Sigal RJ, Yardley JE, Riddell MC, Dunstan DW, Dempsey PC, Horton ES, Castorino K, Tate DF. Physical activity/exercise and diabetes: a position statement of the American Diabetes Association. Diabetes Care. 2016;39:2065-79.

12. Roberts CK, Hevener AL, Barnard RJ. Metabolic syndrome and insulin resistance: underlying causes and modification by exercise training. Compr Physiol. 2013:3:1-58.

13. Snowling NJ, Hopkins WG. Effects of different modes of exercise training on glucose control and risk factors for complications in type 2 diabetic patients: a meta-analysis. Diabetes Care. 2006;29:2518-27. https://doi.org/10. 2337/dc06-1317.

14. Teng Y, Li D, Guruvaiah P, Xu N, Xie Z. Dietary supplement of large yellow tea ameliorates metabolic syndrome and attenuates hepatic steatosis in db/ db mice. Nutrients. 2018;10. https://doi.org/10.3390/nu10010075.
15. Yang CS, Zhang JS, Zhang L, Huang JB, Wang YJ. Mechanisms of body weight reduction and metabolic syndrome alleviation by tea. Mol Nutr Food Res. 2016;60:160-74.

16. Cooper R, Morré DJ, Morré DM. Medicinal benefits of green tea: part I. review of noncancer health benefits. J Altern Complement Med. 2005; 11(3):521-8.

17. Santana $A A D$, Santamarina $A B$, Souza $G$, Mennitti LV, Okuda MH, Venancio $D P$, Seelaender M, Nascimento CMOD, Ribeiro EB, Lira FS, Oyama LM. Decaffeinated green tea extract rich in epigallocatechin-3-gallate improves insulin resistance and metabolic profiles in normolipidic diet--but not highfat diet-fed mice. J Nutr Biochem. 2015;26:893-902.

18. Snoussi C, Ducroc R, Hamdaoui MH, Dhaouadi K, Abaidi H, Cluzeaud F, Nazaret C, Gall ML, Bado A. Green tea decoction improves glucose tolerance and reduces weight gain of rats fed normal and high-fat diet. J Nutr Biochem. 2014:25:557-64.

19. Ahmad RS, Butt MS, Sultan MT, Mushtaq Z, Ahmad S, Dewanjee S, Feo V, Ziaulhap M. Preventive role of green tea catechins from obesity and related disorders especially hypercholesterolemia and hyperglycemia. J Transl Med. 2015;13:79.

20. Hodgson $A B$, Randell RK, Jeukendrup AE. The effect of green tea extract on fat oxidation at rest and during exercise: evidence of efficacy and proposed mechanisms. Adv Nutr. 2013;4:129-40.

21. Xia EH, Zhang HB, Sheng J, Li K, Zhang QJ, Kim C, Zhang Y, Liu Y, Zhu T, Li W, Huang H, Tong Y, Nan H, Shi C, Shi C, Jiang JJ, Mao SY, Jiao JY, Zhang D, Zhao Y, Zhao YJ, Zhang LP, Liu YL, Liu BY, Yu Y, Shao SF, Ni DJ, Eichler EE, Gao LZ. The tea tree genome provides insights into tea flavor and independent evolution of caffeine biosynthesis. Mol Plant. 2017;10(6):866-77.

22. Zhu M, Li N, Zhao M, Yu W, Wu JL. Metabolomic profiling delineate taste qualities of tea leaf pubescence. Food Res Int. 2017;94:36-44.

23. Wang C, Zhang C, Kong Y, Peng X, Li C, Liu S, Du L, Xiao D, Xu Y. A comparative study of volatile components in Dianhong teas from fresh leaves of four tea cultivars by using chromatography-mass spectrometry, multivariate data analysis, and descriptive sensory analysis. Food Res Int. 2017:100:267-75.

24. Yan X, Wang Z, Mei Y, Wang L, Wang X, Xu Q, Peng S, Zhou Y, Wei C. Isolation, diversity, and growth-promoting activities of endophytic bacteria from tea cultivars of Zijuan and Yunkang-10. Front Microbiol. 2018;9:1848. https://doi.org/10.3389/fmicb.2018.01848.

25. Sae Tan S, Rogers CJ, Lambert JD. Decaffeinated green tea and voluntary exercise induce gene changes related to beige adipocyte formation in high fat-fed obese mice. J Funct Foods. 2015;14:210-4.

26. Gahreman D, Heydari M, Boutcher YN, Freund J, Boutcher SH. The effect of green tea ingestion and interval sprinting exercise on the body composition of overweight males: a randomized trial. Nutrients. 2016:8:510. https://doi.org/10.3390/nu8080510.

27. Shimotoyodome A, Haramizu S, Inaba M, Murase T, Tokimitsu I. Exercise and green tea extract stimulate fat oxidation and prevent obesity in mice. Med Sci Sports Exerc. 2005;37:1884-92.

28. Guruvaiah P, Guo H, Li D, Xie Z. Preventive Effect of Flavonol Derivatives Abundant Sanglan Tea on Long-Term High-Fat-Diet-Induced Obesity Complications in C57BL/6 Mice. Nutrients. 2018;10(9).

29. Argmann CA, Violante S, Dodatko T, Amaro MP, Hagen J, Gillespie VL, Buettner C, Schadt EE, Houten SM. Germline deletion of Krüppel-like factor 14 does not increase risk of diet induced metabolic syndrome in male C57BL/6 mice. Biochim Biophys Acta Mol basis Dis. 2017;1863(12):3277-85.

30. Xie Z, Liu D, Liu S, Calderon L, Zhao G, Turk J, Guo Z. Identification of a CAMP-response element in the regulator of G-protein signaling-2 (RGS2) promoter as a key Cis-regulatory element for RGS2 transcriptional regulation by angiontensin II in cultured vascular smooth muscles. J Biol Chem. 2011; 286:44646-58

31. Su W, Xie Z, Guo Z, Duncan MJ, Lutshumba J, Gong MC. Altered clock gene expression and vascular smooth muscle diurnal contractile variations in type 2 diabetic $\mathrm{db} / \mathrm{db}$ mice. Am J Physiol Heart Circ Physiol. 2012;302(3):H621-33.

32. Xie Z, Su W, Liu S, Zhao G, Esser K, Schroder EA, Lefta M, Stauss HM, Guo Z, Gong MC. Smooth-muscle BMAL1 participates in blood pressure circadian rhythm regulation. J Clin Invest. 2015;125:324-36.

33. Wang R, Xiao M, Zhang Y, Ho CT, Wan X, Li D, Xie Z. RNA-sequencing analysis reveals $\mathrm{I}$-theanine regulating transcriptional rhythm alteration in vascular smooth muscle cells induced by dexamethasone. J Agric Food Chem. 2019;67(19):5413-22. 
34. Li X, Wang W, Hou L, Wu H, Wu Y, Xu R, Xiao Y, Wang X. Does tea extract supplementation benefit metabolic syndrome and obesity? A systematic review and meta-analysis. Clin Nutr. 2019. https://doi.org/10.1016/j.clnu.2019. 05.019.

35. Basu A, Sanchez K, Leyva MJ, Wu M, Betts NM, Aston CE, Lyons TJ. Green tea supplementation affects body weight, lipids, and lipid peroxidation in obese subjects with metabolic syndrome. J Am Coll Nutr. 2010;29(1):31-40.

36. Brown AL, Lane J, Coverly J, Stocks J, Jackson S, Stephen A, Bluck L, Coward A, Hendrickx $H$. Effects of dietary supplementation with the green tea polyphenol epigallocatechin-3-gallate on insulin resistance and associated metabolic risk factors: randomized controlled trial. $\mathrm{Br} J$ Nutr. 2009;101(6):886-94.

37. Chen IJ, Liu CY, Chiu JP, Hsu CH. Therapeutic effect of high-dose green tea extract on weight reduction: a randomized, double-blind, placebocontrolled clinical trial. Clin Nutr. 2016:35(3):592-9.

38. Sae-Tan S, Rogers CJ, Lambert JD. Voluntary exercise and green tea enhance the expression of genes related to energy utilization and attenuate metabolic syndrome in high fat fed mice. Mol Nutr Food Res. 2014:58(5):1156-9.

39. Maki KC, Reeves MS, Farmer M, Yasunaga K, Matsuo N, Katsuragi Y, Komikado M, Tokimitsu I, Wilder D, Jones F, Blumberg JB, Cartwright Y. Green tea catechin consumption enhances exercise-induced abdominal fat loss in overweight and obese adults. J Nutr. 2009;139(2):264-70.

40. Martin BJ, McGlory C, MacInnis MJ, Allison MK, Phillips SM, Gibala MJ. Green tea extract does not affect exogenous glucose appearance but reduces insulinemia with glucose ingestion in exercise recovery. J Appl Physiol. 2016;121(6):1282-9.

41. Amozadeh $H$, Shabani $R$, Nazari $M$. The effect of aerobic training and green tea supplementation on cardio metabolic risk factors in overweight and obese females: a randomized trial. Int J Endocrinol Metab. 2018;16(4):e60738.

42. Ueno T, Torimura T, Nakamura T, Sivakumar R, Nakayama H, Otabe S, Yuan X, Yamada K, Hashimoto O, Inoue K, Koga H, Sata M. Epigallocatechin-3gallate improves nonalcoholic steatohepatitis model mice expressing nuclear sterolregulatory element binding protein-1C in adipose tissue. Int J Mol Med. 2009;24:17-22.

43. Lee LS, Choi JH, Sung MJ, Hur JY, Hur HJ, Park JD, Kim YC, Gu EJ, Min B, Kim HJ. Green tea changes serum and liver metabolomic profiles in mice with high-fat diet-induced obesity. Mol Nutr Food Res. 2015;59:784-94.

44. Suzuki T, Kumazoe M, Kim Y, Yamashita S, Nakahara K, Tsukamoto S, Sasaki M, Hagihara T, Tsurudome Y, Huang Y, Maeda-Yamamoto M, Shinoda Y, Yamaguchi W, Yamada K, Tachibana H. Green tea extract containing a highly absorbent catechin prevents diet-induced lipid metabolism disorder. Sci Rep. 2013;3:2749.

45. Krycer JR, Sharpe LJ, Luu W, Brown AJ. The Akt-SREBP nexus: cell signaling meets lipid metabolism. Trends Endocrinol Metab. 2010;21(5):268-76.

46. Liu DD, Han CC, Wan HF, He F, Xu HY, Wei SH, Du XH, Xu F. Effects of inhibiting PI3K-Akt-mTOR pathway on lipid metabolism homeostasis in goose primary hepatocytes. Animal. 2016;10(08):1319-27.

47. Wang S, Huang Y, Xu H, Zhu Q, Lu H, Zhang M, Hao S, Fang C, Zhang D, Wu X, Wang X, Sheng J. Oxidized tea polyphenols prevent lipid accumulation in liver and visceral white adipose tissue in rats. Eur J Nutr. 2016;56:2037-48.

48. Rocha ALS, Bolin AP, Cardoso CAL, Otton R. Green tea extract activates AMPK and ameliorates white adipose tissue metabolic dysfunction induced by obesity. Eur J Nutr. 2016;55:2231-44.

49. Achten J, Jeukendrup AE. Optimizing fat oxidation through exercise and diet. Nutrition. 2004:20:716-27.

50. Coggan AR, Raguso CA, Gastaldelli A, Sidossis LS, Yeckel CW. Fat metabolism during high-intensity exercise in endurance-trained and untrained men. Metabolism. 2000;49:122-8.

51. Murase T, Haramizu S, Shimotoyodome A, Tokimitsu I. Reduction of dietinduced obesity by a combination of tea-catechin intake and regular swimming. Int J Obes. 2006;30(3):561-8.

52. Baker RG, Hayden MS, Ghosh S. NF-KB, inflammation, and metabolic disease. Cell Metab. 2011;13:11-22. https://doi.org/10.1016/j.cmet. 2010.12.008.

53. Minihane AM, Vinoy S, Russell WR, Baka A, Roche HM, Tuohy KM, Teeling JL, Blaak EE, Fenech M, Vauzour D, McArdle HJ, Kremer BH, Sterkman L, Vafeiadou K, Benedetti MM, Williams CM, Calder PC. Low-grade inflammation, diet composition and health: current research evidence and its translation. Br J Nutr. 2015:114:999-1012.

54. King GL. The role of inflammatory cytokines in diabetes and its complications. J Periodontol. 2008;79(8 Suppl):1527-34

55. Ma S, Huang Q, Tominaga T, Liu C, Suzuki K. An 8-week ketogenic diet alternated interleukin-6, ketolytic and lipolytic gene expression, and enhanced exercise capacity in mice. Nutrients. 2018;10(11):1696.

56. Cialdella-Kam L, Ghosh S, Meaney MP, Knab AM, Shanely RA, Nieman DC. Quercetin and green tea extract supplementation downregulates genes related to tissue inflammatory responses to a 12-week high fat-diet in mice. Nutrients. 2017:9(7):773.

57. Sun SC. The noncanonical NF-KB pathway. Immunol Rev. 2012;246:125-40.

58. Tipoe GL, Leung TM, Liong EC, Lau TY, Fung ML, Nanji AA. Epigallocatechin3-gallate (EGCG) reduces liver inflammation, oxidative stress and fibrosis in carbon tetrachloride (CCl4)-induced liver injury in mice. Toxicology. 2010; 273:45-52.

59. Murase T, Haramizu S, Ota N, Hase T. Tea catechin ingestion combined with habitual exercise suppresses the aging-associated decline in physical performance in senescence-accelerated mice. Am J Physiol Regul Integr Comp Physiol. 2008;295(1):R281-9.

60. Wu E, Zhang T, Tan C, Peng C, Chisti Y, Wang Q, Gong J. Theabrownin from Pu-erh tea together with swinging exercise synergistically ameliorates obesity and insulin resistance in rats. Eur J Nutr. 2019. https://doi.org/10 1007/s00394-019-02044-y.

61. Beals JW, Burd NA, Moore DR, van Vliet S. Obesity alters the muscle protein synthetic response to nutrition and exercise. Front Nutr. 2019;6:87. https:// doi.org/10.3389/fnut.2019.00087.

62. Beals JW, Skinner SK, McKenna CF, Poozhikunnel EG, Farooqi SA, van Vliet S, Martinez IG, Ulanov AV, Li Z, Paluska SA, Burd NA. Altered anabolic signaling and reduced stimulation of myofibrillar protein synthesis after feeding and resistance exercise in people with obesity. J Physiol. 2018;596(21):5119-33.

63. Haramizu S, Ota N, Hase T, Murase T. Catechins suppress muscle inflammation and hasten performance recovery after exercise. Med Sci Sports Exerc. 2013;45(9):1694-702.

64. Stuart CA, Wen G, Williamson ME, Jiang J, Gilkison CR, Blackwell SJ, Nagamani M, Ferrando AA. Altered GLUT1 and GLUT3 gene expression and subcellular redistribution of GLUT4: protein in muscle from patients with acanthosis nigricans and severe insulin resistance. Metabolism. 2001;50(7):771-7.

65. Tsai TW, Chang CC, Liao SF, Liao YH, Hou CW, Tsao JP, Cheng IS. Effect of green tea extract supplementation on glycogen replenishment in exercised human skeletal muscle. Br J Nutr. 2017;117(10):1343-50.

66. Karlsson HK, Ahlsén M, Zierath JR, Wallberg-Henriksson H, Koistinen HA. Insulin signaling and glucose transport in skeletal muscle from first-degree relatives of type 2 diabetic patients. Diabetes. 2006;55(5):1283-8.

67. Pan H, Guo J, Su Z. Advances in understanding the interrelations between leptin resistance and obesity. Physiol Behav. 2014;130:157-69.

68. Murase T, Haramizu S, Shimotoyodome A, Tokimitsu I, Hase T. Green tea extract improves running endurance in mice by stimulating lipid utilization during exercise. Am J Physiol Regul Integr Comp Physiol. 2006;290: R1550eR1556.

\section{Publisher's Note}

Springer Nature remains neutral with regard to jurisdictional claims in published maps and institutional affiliations.

Ready to submit your research? Choose BMC and benefit from:

- fast, convenient online submission

- thorough peer review by experienced researchers in your field

- rapid publication on acceptance

- support for research data, including large and complex data types

- gold Open Access which fosters wider collaboration and increased citations

- maximum visibility for your research: over $100 \mathrm{M}$ website views per year

At $\mathrm{BMC}$, research is always in progress.

Learn more biomedcentral.com/submissions 